\title{
Formation of plant cuticle: evidence for the occurrence of the peroxygenase pathway
}

\author{
José Lequeu ${ }^{1}$, Marie-Laure Fauconnier ${ }^{2}$, Antoine Chammai ${ }^{3}$, Roberte Bronner ${ }^{4}$ and Elizabeth Blée ${ }^{1, *}$ \\ ${ }^{1}$ Laboratoire des Phytooxylipines, IBMP-CNRS-UPR 2357, 28-Rue Goethe, 67083 Strasbourg-Cedex, France, \\ ${ }^{2}$ Faculté Universitaire des Sciences Agronomiques, 2, Passage Des Déportés-5030, Gembloux, Belgique, \\ ${ }^{3}$ Institut de Botanique-ULP, 28-Rue Goethe, 67083 Strasbourg-Cedex, France, and \\ ${ }^{4}$ Laboratoire de Cytologie, IBMP-CNRS-UPR 2357, 12-Rue du Général Zimmer, 67000 Strasbourg, France
}

Received 1 April 2003; revised 7 July 2003; accepted 10 July 2003.

*For correspondence (fax +33 3902418 84; e-mail Elizabeth.Blee@ibmp-ulp.u-strasbg.fr).

\begin{abstract}
Summary
Cuticle plays a major role as a protective barrier in plants. Despite its physiological importance, the mode of formation of this complex structure remains poorly understood. In particular, none of the putative enzymes involved in the biosynthesis of the cutin, the matrix of cuticle, have been cloned. We have shown previously that peroxygenase is able to catalyze in vitro the epoxidation step required for the biosynthesis of $\mathrm{C18}$ cutin monomers. In the present work, we have confirmed in planta that this oxidase is indeed a key enzyme involved in the formation of cutin. Thus, in maize leaves, the specific inactivation of peroxygenase by organophosphorothioates resulted in a dramatic decrease of cuticular epoxide content, as visualized by a specific histochemical technique that was accompanied by a reduced thickness of the cuticle. A strict correlation could also be established between the extent of inhibition of the peroxygenase and the modification of the cuticle triggered by a family of structurally related inhibitors. Importantly, these effects were restricted to plants that contain a cutin originating from C18 monomers. The altered cuticle of maize, treated with the peroxygenase inhibitor, was characterized by an increased permeability to pesticides. In addition, such plants became largely susceptible to infection by fungi, implying that the cuticle represents a crucial target for the modulation of the response in plant-pathogen interactions.
\end{abstract}

Keywords: peroxygenase, cutin biosynthesis, organophosphorothioate, suicide inhibition.

Introduction

The function of the cuticle, which covers all the aerial parts of a plant, was classically restricted to that of a protective layer. Indeed, as the first barrier between the plant and its environment, the cuticle plays a key role in providing protection from mechanical damage, ultraviolet radiation, or penetration of xenobiotics and pathogens (Baur, 1997; Kersteins, 1996). Subsequently, it was demonstrated to regulate the absorption and transpiration of water and various solutes (Schönherr, 2000; Schreiber, 2001). However, recent biochemical and genetic approaches revealed that the cuticle is 'more than just a surface thing' (Smith, 1999). Mutants with reduced or perturbed cuticles exhibit abnormally fused organs, highlighting the idea that cuticles are essential elements for delimitation of organs during plant development (Jenks et al., 1996; Sieber et al., 2000; Sinha and Lynch, 1998). Moreover, it has been shown that components of the cutin, constituting the framework of the cuticle, act as signal molecules in both plants and pathogens. For example, they trigger the first plant defense responses and the disease resistance in barley (Schweizer et al., 1996a,b). They also behave as biochemical cues to induce appressorium differentiation required by fungi, such as $\mathrm{Mag}$ naporthe grisea, to penetrate plant cells (DeZwaan et al., 1999; Gilbert and Dean, 1996; Pruitt et al., 2000).

Strikingly, despite the physiological importance of the cutin, the mechanism for its formation and regulation remains elusive. For example, little is known about where the monomers and oligomers are formed, how they are transferred to the cell surface, and by what process they are polymerized. Cutin is composed of a network of interesterified hydroxy and epoxy derivatives of $\mathrm{C} 16$ and $\mathrm{C} 18$ fatty acids. Since the pioneering work of Kolattukudy and his collaborators, who elaborated the first general cutin biosynthetic pathway, the implicated enzymes have not yet 
been purified or cloned (Kolattukudy et al., 1973). We have proposed a new scheme for the formation of the C18 family of cutin monomers (Blée and Schuber, 1993), involving a peroxygenase responsible for the catalysis of the epoxidation step. We have demonstrated that this enzyme, associated with a membrane-bound epoxide hydrolase and a cytochrome $\mathrm{P} 450$, can catalyze in vitro the formation of $\mathrm{C} 18$ cutin acids (Blée and Schuber, 1993). Concerning the identity of the relevant cytochrome P450, CYP $94 \mathrm{~A} 1$ has been recently suggested to be in charge of the $\omega$-oxidation of such cutin monomers (Pinot et al., 1999). However, the involvement of any of these putative enzymes in the biosynthesis of cutin has never been confirmed in planta. Analysis of mutants altered in cutin composition may help to elucidate the formation of this structural component, but such mutants have not yet been isolated. An alternative approach would be to modify the cutin by hampering some steps in its biosynthesis. For example, by inhibiting the formation of epoxides required for the reticulation of the cutin, one could expect to change the aspect and the properties of the cuticle and also to reduce the formation of the most active cutin monomer in signaling, i.e. cis-9,10epoxy-18-hydroxystearic acid. Therefore, we have inhibited in planta the peroxygenase and have addressed the following questions: (i) Could the modification of peroxygenase activity affect and regulate the quantity or composition of cutin and/or cuticle formation? (ii) Could the peroxygenase inactivation influence the defenses of the plant?

\section{Results}

\section{Inhibition of plant peroxygenase by organophosphorothioates}

In our search for specific inhibitors of peroxygenase activity, we probed the effects of organophosphorothioates. Experiments were carried out with peroxygenase purified from oat and soybean seedlings. First, we found that the peroxygenase of both species was able to catalyze desulfuration of $\left[{ }^{14} \mathrm{C}\right]$-ring-UL-parathion to radiolabeled paraoxon at appreciable rates, albeit only $20 \pm 5 \%$ SD of the total substrate could be metabolized as a result of the rapid inactivation of the enzymes (Figure 1). Second, we noticed that epoxidation of oleic acid catalyzed by purified peroxygenases was inhibited in a time-dependent manner by parathion, according to pseudo-first order kinetics $\left(K_{\text {inac }}=\right.$ $40 \pm 10 \mu \mathrm{M}$ and $\tau_{1 / 2}=3.5 \pm 1.2 \mathrm{~min}$ for oat peroxygenase, and $K_{\text {inac }}=74 \pm 25 \mu \mathrm{M}, \tau_{1 / 2}=1.15 \pm 0.6$ min for soybean peroxygenase; Figure 2), characteristic of a suicide inhibition reaction. As expected, paraoxon, the oxoanalog of parathion, had no effect on oleic acid epoxidase activity (Table 1). A screening of a panel of organophosphorothioates, in order to establish possible structure-function rela-

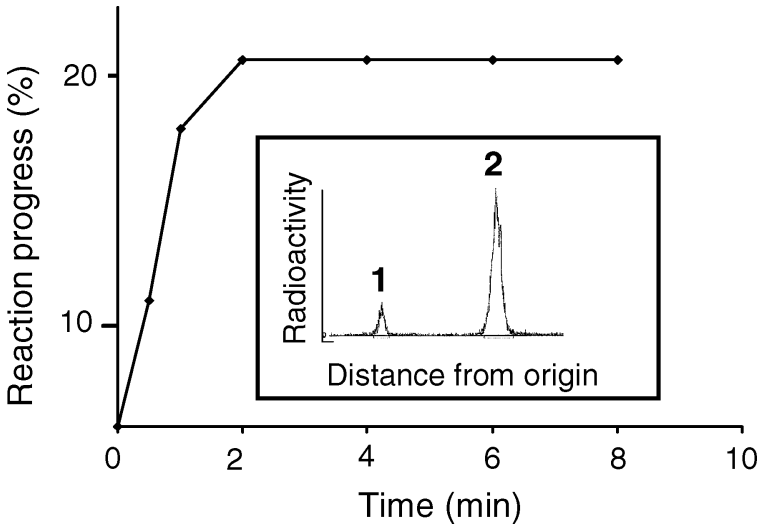

Figure 1. Metabolism of parathion by soybean peroxygenase. Parathion ethyl $(250 \mu \mathrm{M})$ was incubated in presence of purified soybean peroxygenase $(5 \mu \mathrm{g})$ and cumene hydroperoxide $(1 \mathrm{mM})$ in $0.1 \mathrm{M} \mathrm{KH}_{2} \mathrm{PO}_{4}$ buffer, pH 7 (final volume $50 \mu \mathrm{l}$ ) at $26^{\circ} \mathrm{C}$. Insert: identification by TLC of the paraoxon formed by incubation of radioactive parathion with peroxygenase over 5 min. Peak 1: paraoxon; peak 2: parathion.

tionship, revealed that terbufos was a better inhibitor than parathion (Table 1). The terbufos structure contains two other sulfur atoms, which could add a time-independent (competitive) inhibition, and accordingly, a value of $K_{\mathrm{i}}=10 \mu \mathrm{M}$ as constant inhibition has been determined. It is worth noting that terbufos appeared to only inactivate peroxygenase because the activities of the other enzymes potentially involved in cutin formation, i.e. soluble lipoxygenase, epoxide hydrolase, P450-dependent $\omega$-oxidase, or

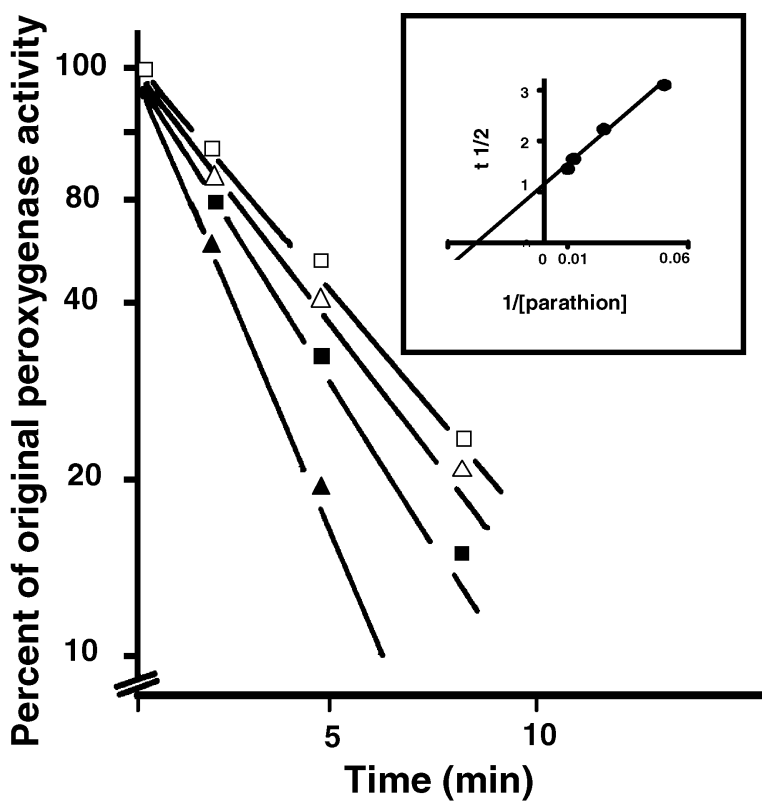

Figure 2. Semilog plot of the loss of peroxygenase activity as a function of time of incubation of purified soybean enzyme with different concentrations of parathion $(\square): 20 \mu \mathrm{M} ;(\triangle): 40 \mu \mathrm{M} ;(\square): 80 \mu \mathrm{M} ;(\boldsymbol{\Delta}): 100 \mu \mathrm{M}$. The insert shows a replot of $\tau_{1 / 2}$ values against the reciprocal of the corresponding inhibitor concentrations. 
Table 1 Inhibition of the peroxygenase and its relationship to the modification of the cuticle

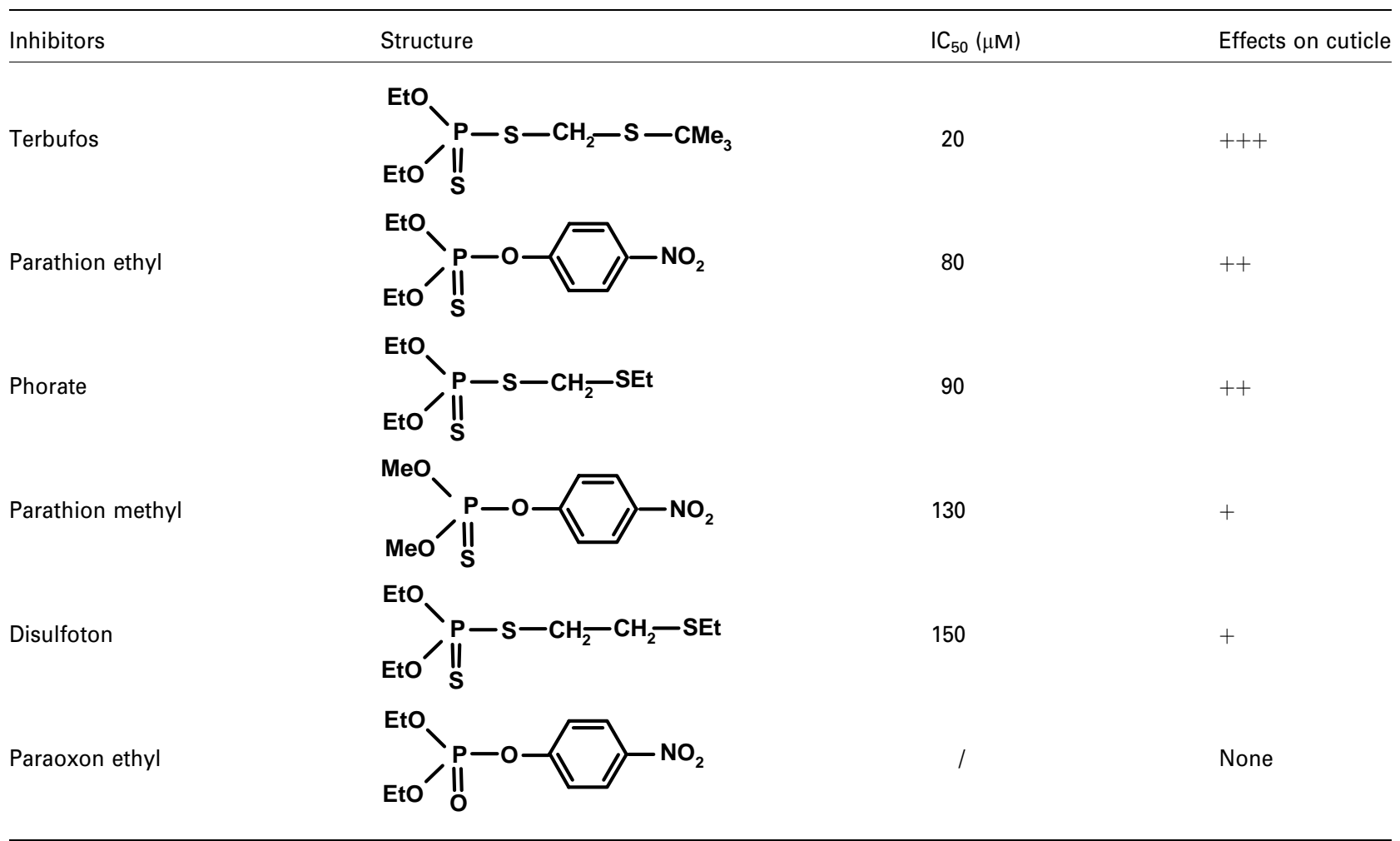

Transverse sections of two leaves from four plants were observed by fluorescent microscopy and pictures of these microscopic observations were analyzed. Description of the alteration of cuticular aspects caused by treatments with organophosphorothioates are as follows: $(+++)$ severe damage of the cuticle that was completely or partly absent; $(++)$ disrupted cuticle; $(+)$ thinner cuticle.

elongase, were not affected by terbufos at the concentrations used in these experiments (Table 2).

\section{Cutin composition}

Large differences have been found in cutin composition depending on the species and age of the plant, and also between leaves, fruits, and stems of a single species (Riederer and Schönherr, 1988). Therefore, we sought to determine the $\mathrm{C} 16 / \mathrm{C} 18$ ratio of the cutin monomers present in the leaves of the crops studied (Table 3). It appears that, although soybean seedlings represent a suitable source for the preparation of highly purified and active peroxygenase required for our mechanistic studies, soybean leaves pos- sess only a very low content of $\mathrm{C} 18$ cutin monomers, which made them inappropriate for our in planta experiments. Therefore, we have switched to maize seedlings as a model system because this plant is representative of a $\mathrm{C} 16 / \mathrm{C} 18$ mixed cutin family and has also an important value in the agrochemical industry.

\section{Maize peroxygenase inhibition by organophosphorothioates}

First, we have verified that maize peroxygenase, although exhibiting a specific activity almost five times lower than that of the soybean enzyme, was also inactivated through a mechanism-based process by organophosphorothioates.

Table 2 In vitro effects of terbufos on enzymes involved in cutin biosynthesis

\begin{tabular}{llcccc}
\hline & Lipoxygenase & Epoxide hydrolase & $\omega$-Hydroxylase & Elongase & Peroxygenase \\
\hline Control & 100 & 100 & 100 & 100 & 100 \\
Terbufos $(10 \mu \mathrm{M})$ & 107 & 120 & 83 & 80 & 48 \\
Terbufos $(20 \mu \mathrm{M})$ & 86 & 89 & 119 & 110 & 27 \\
\hline
\end{tabular}

The enzyme activities were determined in the presence of different concentrations of terbufos, according to procedures described in the section under Experimental procedures. The data are given in percentage relative to control and are means of two independent measurements that did not differ by more than $20 \%$.

(C) Blackwell Publishing Ltd, The Plant Journal, (2003), 36, 155-164 
Table 3 C16 and C18 cutin monomer proportions from different crops cuticles

\begin{tabular}{lll}
\hline Plants & $\begin{array}{l}\text { C16 cutin } \\
\text { monomers (\%) }\end{array}$ & $\begin{array}{l}\text { C18 cutin } \\
\text { monomers (\%) }\end{array}$ \\
\hline Barley & 15 & 85 \\
Oat & 30 & 70 \\
Maize & 47.5 & 52.5 \\
Tobacco & 68.1 & 31.9 \\
Vetch & 89 & 11 \\
Pea & 90.3 & 9.7 \\
Soybean & 95.2 & 4.8 \\
\hline
\end{tabular}

C16 cutin monomers represent 9,16-dihydroxyhexadecanoic and 10,16-dihydroxyhexadecanoic acids, whereas C18 cutin monomers are the sum of the 18-hydroxyocta-9-decenoic, 9,10-epoxy18-hydroxyoctadecanoic, and 9,10,18-trihydroxyoctadecanoic acids. Results are the means of two independent experiments that did not differ by more than $25 \%$.

Indeed, microsomes from maize seedlings catalyze desulfuration of parathion to paraoxon, and under our experimental conditions at an optimal pH of 6.5, an apparent $K_{\mathrm{m}}$

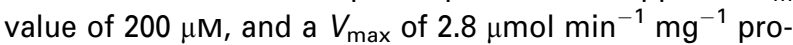
tein were calculated for the sulfur substrate. Peroxygenase activity was also strongly inhibited by terbufos, and $\mathrm{IC}_{50}$ of $20 \mu \mathrm{M}$ could be determined. Maize seeds were germinated in the presence or absence of $300 \mu \mathrm{M}$ terbufos (equivalent to 100 p.p.m., concentration generally used in field conditions). After 7 days, no visual phenotype of the seedlings could be observed. However, the treated plants contained less than $80 \%$ of the initial peroxygenase activity, confirming the in planta inactivation of the enzyme by terbufos (Figure 3).

\section{Effect of terbufos on maize leaf permeability}

In order to test to what extent the inhibition of the peroxygenase could influence the physical properties of leaves, we have examined the effect of the soil-applied insecticide terbufos on the leaf uptake of $\left[{ }^{14} \mathrm{C}\right]$ primisulfuron and $\left[{ }^{14} \mathrm{C}\right]$ metolachlor in 7-day-old maize. The lipophilic nature of the herbicide metolachlor facilitated its penetration through the cuticular lipids. For example, after only $2 \mathrm{~h}$ of application, $32 \pm 5 \%$ of the total applied herbicide had already penetrated into the leaves. Treating maize with terbufos dramatically increased the uptake up to $70 \pm 4 \%$. In contrast, the uptake of $\left[{ }^{14} \mathrm{C}\right]$ primisulfuron was severely impeded by cuticular waxes, and the addition of a small amount of detergent was necessary for this herbicide to penetrate the maize leaves. However, corn plants grown for 7 days in terbufos solutions, which then received a foliar application of the herbicide, absorbed primisulfuron three times as much as did plants not treated with terbufos.

\section{Effect of terbufos on maize cuticle formation}

In an effort to observe a possible perturbation of the cutin structure that could be the cause of the change in cuticular permeability, transverse sections of leaves of maize were examined by fluorescence microscopy. In untreated corn, the cuticle stained with the fluorochrome dye auramine $O$ appeared as a bright yellow unbroken line at the surface of the living epidermal cells (Figure 4a). In sharp contrast, this line was disrupted, and in some cases, in sections of leaves of maize grown for 7 days in terbufos-treated soils, it was totally absent (Figure 4b). Therefore, we have investigated if such a dramatic difference in the cuticle might have resulted to some degree from the inhibition of epoxide biosynthesis. Ultrahistochemical tests developed by Holloway et al. (1981) provide direct evidence of the presence of epoxides in cuticles of higher plants. The epoxy groups were visualized as dark silver precipitates covering the surface of the leaf of the control corn (Figure 4e). Strikingly, such epoxy functions had largely disappeared from the cuticle of terbufos-treated maize (Figure 4f). Analysis by gas chromatography coupled with mass spectra (GC-MS) of the cutin composition of control and

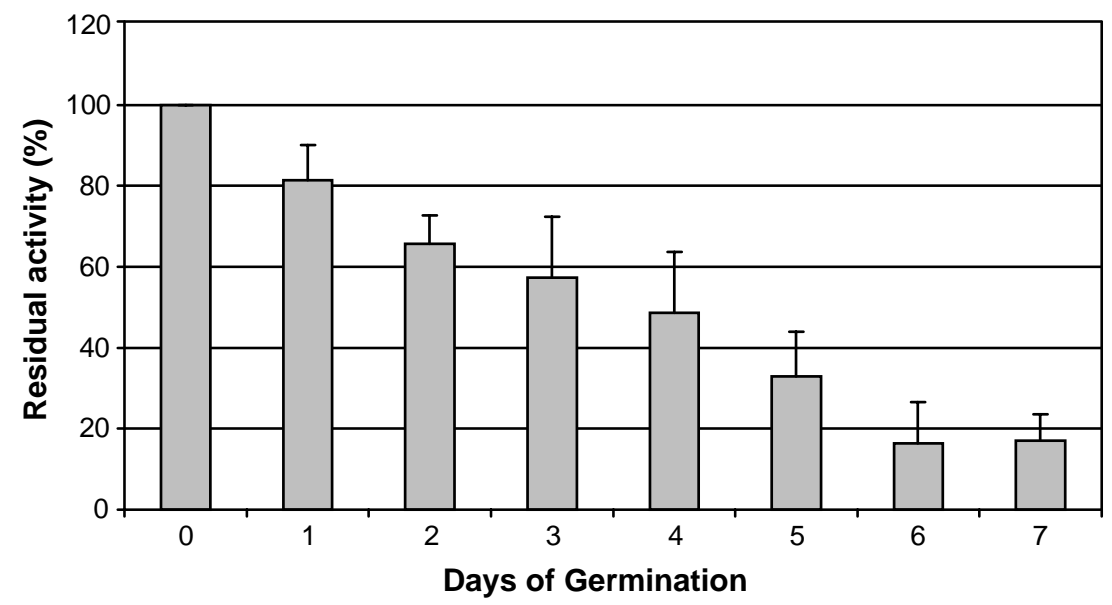

Figure 3. Residualactivityofperoxygenaseingerminating maize treated with terbufos $(300 \mu \mathrm{M})$ versus untreated plants. Peroxygenase activity present in seeds was $26 \pm 8 \mathrm{nmol} \mathrm{min}{ }^{-1} \mathrm{mg}^{-1}$ proteins. Bars of errors represent three independent experiments.

(C) Blackwell Publishing Ltd, The Plant Journal, (2003), 36, 155-164 

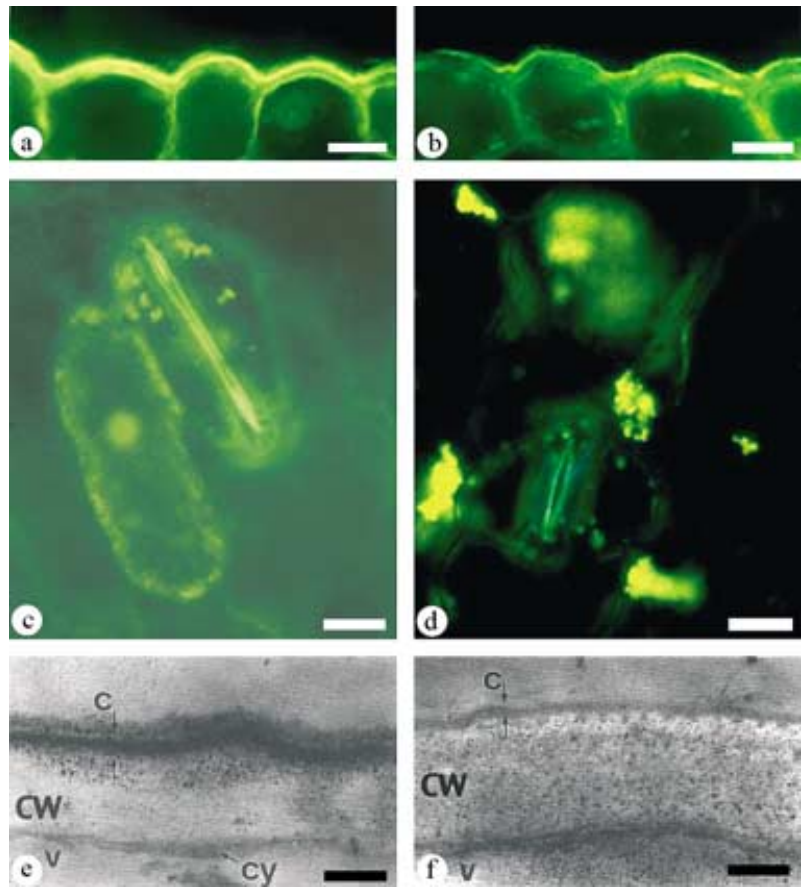

Figure 4. Microscopic studies of maize cuticles.

Observation by fluorescence microscopy of transversal cuts and surface leaves (dyed with auramine 0 ) of maize untreated $(a, c)$ or treated $(b, d)$ with $300 \mu \mathrm{M}$ of terbufos. Bars: $10 \mu \mathrm{m}$. Visualization of epoxy functions in cuticles of maize untreated (e) or treated ( $f$ ) with terbufos by electron microscopy using specific staining techniques described by Holloway et al. (1981). C: cuticle; cw: cell wall; cy: cytoplasm; v: vacuole. Bars: $0.5 \mu \mathrm{m}$.

terbufos-treated plants showed a reduction by about a factor 2 of the amount of both 9,10-epoxy-18-hydroxystearic acid and its trihydroxy fatty acid derivative in the insecticide-treated maize (Table 4), thus confirming the in vivo inhibition of the biosynthesis of the cutin-epoxy esters. It should be noted that the amount of the other C18 cutin monomer $\omega$-hydroxystearic acid was doubled in the leaf cutin of terbufos-treated maize during the same time.

Ultrastructural studies have also revealed that the reduced amount of one of the components involved in cutin secondary reticulation led unexpectedly to the formation of thinner cuticle by at least a factor 2 . The modification of the thickness of maize cuticle under treatment with terbufos was also visualized by fluorescent microscopy. The foliar surface of untreated maize exhibited a yellowgreen background because of the fluorescence of the cuticle stained with auramine $\mathrm{O}$ (Figure 4c). In sharp contrast, this green color faded in leaves of treated plants where a bluish autofluorescence of the underlying tissues predominated, supporting the idea of a thinning of the maize cuticle during the treatment with terbufos (Figure $4 d$ ).

\section{Structure-function relationship}

Altogether, our results support a possible physiological impact of the peroxygenase on the biosynthesis of cutin monomers in maize plants. Moreover, this enzyme seemed to play a determinant role in the control of the structure and the properties of the corn cuticle. However, such results raised several questions regarding the specificity of the phenomenon we have observed.

The first query concerns the demonstration of a connection between the degree of inhibition of the peroxygenase and the extent of the modification of the maize cuticle. In order to address this question, we treated maize with different organophosphorothioates, with previously determined capacities for inhibiting the peroxygenase, and the effects of these chemicals on the cuticle were examined using fluorescent microscopy. A strict relationship could be

Table 4 Composition of $\mathrm{C} 16$ and C18 cutin monomers of leaves of maize and barley untreated and treated with terbufos (300 $\mu \mathrm{M})$

\begin{tabular}{|c|c|c|c|c|}
\hline Conditions & $\begin{array}{l}9,16 \text { and } 10,16 \text {-dihydroxy- } \\
\text { hexadecanoic acid C16 (\%) }\end{array}$ & $\begin{array}{l}\omega \text {-Hydoxystearic acid, } \\
18: 1(\%)\end{array}$ & $\begin{array}{l}\text { 9,10-epoxy-18-hydroxy- } \\
\text { octadecanoic acid (\%) }\end{array}$ & $\begin{array}{l}\text { 9,10,18-trihydroxy- } \\
\text { octadecanoic acid (\%) }\end{array}$ \\
\hline \multicolumn{5}{|c|}{ Untreated maize } \\
\hline Stage A & 47.5 & 12.3 & 34.9 & 4.8 \\
\hline Stage B & 8.6 & 52.3 & 18.5 & 20.6 \\
\hline \multicolumn{5}{|c|}{ Treated maize } \\
\hline Stage A & 47.9 & 28.2 & 23.1 & 2.1 \\
\hline Stage B & 8.2 & 62.2 & 15.6 & 12.8 \\
\hline \multicolumn{5}{|c|}{ Untreated barley } \\
\hline Stage A & 15 & 7 & 78 & nd \\
\hline Stage B & 5.9 & 16.4 & 76.6 & 0.8 \\
\hline \multicolumn{5}{|c|}{ Treated barley } \\
\hline Stage A & 15.2 & 6.3 & 78.5 & nd \\
\hline Stage B & 5.4 & 15.2 & 77.9 & 1.2 \\
\hline
\end{tabular}

Cutin monomers were extracted and analyzed by GC-MS as described in the section under Experimental procedures. Plants at stage A were young seedlings with yellowish leaves $2-5 \mathrm{~cm}$ long. Plants at stage B possess green $10-20-\mathrm{cm}$-long leaves. Values were the means of two independent analyses that did not differ by more than $5 \%$; nd: not detectable.

(C) Blackwell Publishing Ltd, The Plant Journal, (2003), 36, 155-164 
Table 5 Infection of maize untreated and treated by terbufos (300 $\mu \mathrm{M})$ by $C$. heterostrophus

\begin{tabular}{|c|c|c|c|c|c|c|c|c|}
\hline \multirow{3}{*}{$\begin{array}{l}\text { Symptoms } \\
\text { No symptom }\end{array}$} & \multicolumn{4}{|c|}{ Untreated maize } & \multicolumn{4}{|c|}{ Terbufos-treated maize } \\
\hline & \multicolumn{2}{|c|}{ First leaf } & \multicolumn{2}{|c|}{ Second leaf } & \multicolumn{2}{|c|}{ First leaf } & \multicolumn{2}{|c|}{ Second leaf } \\
\hline & 14 & 9 & 3 & 23 & l & l & 1 & 3 \\
\hline Stage A & 12 & 16 & 23 & 2 & 9 & 3 & 5 & 3 \\
\hline Stage B & l & l & l & l & 12 & 14 & 13 & 16 \\
\hline Stage C & l & l & l & l & 6 & 10 & 8 & 5 \\
\hline Total plants & 26 & 25 & 26 & 25 & 27 & 27 & 27 & 27 \\
\hline
\end{tabular}

Inoculations were made on the first leaf of 7-day-old maize seedlings. The second leaf developed after the inoculation. Symptoms of fungal infection were observed 7 days after the inoculation. Stage A: small yellow spots on the leaves; stage B: spots enlarged and turned redbrown; stage C: spots were dark brown and leaves started to curl. Two independent experiments are represented.

established between inhibition of the peroxygenase activity and the modification of the cuticle triggered by the original inhibitor or its chemical analogs (Table 1).

A second issue involves the limited response of the plants to terbufos treatment when these plants did not contain $\mathrm{C} 18$ cutin monomers and thus did not require a peroxygenasecatalyzed epoxidation step for the biosynthesis of their cuticle. The cutin of soybean or pea leaves contains mostly C16 alkanoic acids (Table 3). We were unable to distinguish any modification of the cuticle of these plants when they were treated with the insecticide terbufos. On the contrary, cereals such as barley possess cutins predominately composed of $\mathrm{C} 18$ monomers. It was observed that the thickness of the cuticle for leaves of barley treated with terbufos was diminished by $2-2.5$-fold $(n=30)$. Thus, it appears that modification of the cuticle provoked by inhibition of the peroxygenase with terbufos was restricted to plants coated with a cutin rich in $\mathrm{C} 18$ monomers.

No variation between the amounts of the different $\mathrm{C} 18$ monomers could be detected when we analyzed the cutin composition of treated barley leaves with GC-MS. On the other hand, the content in oleic acid, the common precursor for $\mathrm{C} 18$ cutin monomers, doubled in leaves of terbufostreated barley.

\section{Effect of terbufos treatment on maize infection by fungus}

Cochliobolus heterostrophus is a filamentous fungus, which causes southern leaf maize blight, particularly ruinous in American corn fields in 1970. The symptoms of the disease are spots developing between veins in the area of inoculation with yellow green color (stage $A$ ), which later enlarge and turn dark reddish brown (stage B) until finally the leaves become brown and curl up (stage C). Maize plants infected by the fungi showed a complete absence of spots or stage B and C symptoms after 14-day postinoculation (Table 5). In sharp contrast, at the same time of inoculation, the fungus had successfully infected the seedlings treated with terbufos as about 51 and $28 \%$ of the

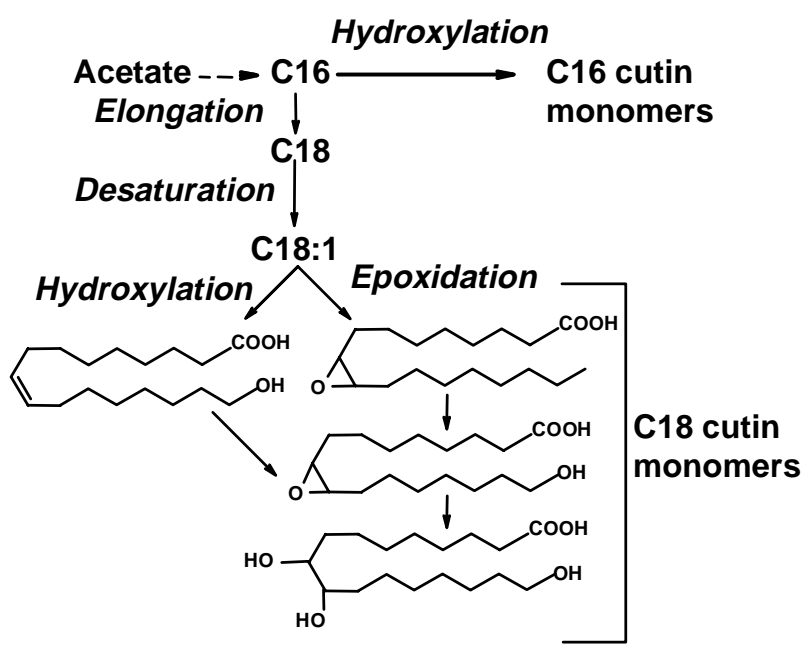

Figure 5. Hypothetical scheme for the biosynthesis of cutin monomers.

leaves of these treated plants presented symptoms of stages $B$ and $C$, respectively (Table 5 ).

\section{Discussion}

We have previously shown that the epoxidation step required in the biosynthesis of $\mathrm{C} 18$ cutin monomers could be catalyzed in vitro by plant peroxygenase (Blée and Schuber, 1993). But at that time, we did not establish a concrete biological connection to cutin formation. Therefore, our aim here was to provide unequivocal proof for the involvement, in vivo, of such an enzyme in cutin biosynthesis. For this purpose and because the gene coding for plant peroxygenase remains uncloned, we have chosen a 'pharmacological' approach and therefore have searched for a specific inhibition of the epoxidation step catalyzed by the peroxygenase.

In mammals, epoxidation of double bonds of unsaturated long-chain fatty acids are generally accomplished by cytochromes P450. Although plant peroxygenase shares with 
cytochromes $\mathrm{P} 450$ and peroxidases the ability to achieve hydroperoxide-dependent oxidations, it proceeds in quite a unique fashion. Briefly, it catalyzes the direct transfer of one oxygen from a hydroperoxide, which will be reduced to its corresponding alcohol, a substrate, which will be oxidized (Blée et al., 1993). Hence, peroxygenase catalyzes co-oxidations such as fatty acid epoxidation and sulfoxidation reactions that can proceed competitively, although in favor of the sulfoxidation (Blée and Schuber, 1989, 1990). Indeed, in the presence of both oleic acid and the herbicide ethyl propyl thiocarbamate (EPTC), the peroxygenase prevailed in the sulfoxidation of the thiocarbamate at the expense of a reduced formation of 9,10-epoxystearate (Blée, 1991). Therefore, sulfur compounds appeared to be suitable inhibitors for the epoxidation step in cutin biosynthesis. Nevertheless, we were looking for mechanism-based inhibitors that could inactivate peroxygenase activity more specifically. Organophosphorothioates have been found to act as suicide inhibitors for mammalian cytochromes P450, the best studied example being the inactivation of rat or human liver cytochromes $\mathrm{P} 450$ by parathion (Butler and Murray, 1997; Halpert and Neal, 1981). Evidence exists that the oxidation of the sulfide function of this molecule leads to the release of atomic sulfur as a reactive species, which then binds to the protein moiety of the cytochrome P450. Consequently, parathion undergoes an oxidative desulfuration to paraoxon (Ortiz de Montellano and Correia, 1995).

Our results strongly suggest that plant peroxygenase can be inactivated by parathion according to a similar mechanism-based process. First, purified soybean and oat peroxygenases were able to catalyze the desulfuration of parathion, and second, they underwent paracatalytic inactivation by this insecticide. Among the organophosphorothioates tested, terbufos was not only found to react as a strong covalent inhibitor of the plant peroxygenase in vitro, but was also very potent for inactivating such an enzyme in planta.

The details of how the different cutin monomers are netted together are largely unknown. It is generally thought that the architecture of the cutin is built upon hydroxy fatty acids linked by ester bonds derived from primary and secondary alcohols. The latter are presumed to have derived from epoxy fatty acids after their hydrolysis by an epoxide hydrolase (Blée and Schuber, 1993; Kolattukudy et al., 1973). We postulated that the inhibition of the peroxygenase might lead to a reduced amount of these hydroxy fatty acids and to the creation of looser meshes in the cutin netting. This in turn could lead to better permeability of the cuticle. Unexpectedly, it turned out that the reduced formation of hydroxy and epoxy fatty acids, because of the inhibition of the peroxygenase, led to a restricted accumulation of the whole cuticle rather than to a structurally modified cutin. However, we have noticed a modification of the cutin composition in leaves of maize seedlings soil-treated with terbufos that was non-existent in treated barley plants. An explanation for such a discrepancy may originate from the differential activity of the $\omega$ hydroxylase present in these two species. Based on the biosynthetic scheme, we proposed in Figure 5 that oleic acid could be a substrate for $\omega$-hydroxylation by a cytochrome P450 or for epoxidation by a peroxygenase. The inhibition of the peroxygenase would shift the direction of biosynthesis toward the hydroxy derivative, particularly in the case of high $\omega$-hydroxylase activity such as that found in maize. Conversely, a low amount of the hydroxy fatty acids could be detected in the cuticle of barley leaves, and the inhibition of the peroxygenase yielded an accumulation of oleic acid, the common substrate.

Structural studies of terbufos-treated maize leaves confirmed both the reduction of the thickness of the cuticle and the dramatic decrease of the epoxy groups usually present in this layer. Epoxy fatty acids are precursors of the vicinal diols engaged into cutin reticulation via ester bond formation; in addition, they also participate in the formation of ether bonds involved in the cross-links that are present in cutan, i.e. the core of the cuticle that cannot be de-polymerized by treatments that cleave ester bonds (Villena et al., 1999). The inhibition of the peroxygenase impeded the formation of epoxy and derived dihydroxy fatty acids present in cutin, and possibly also those necessary for the biosynthesis of the cutan. Thus, our results revealed a more complex regulation of the cuticle expansion than generally thought. It seems likely that the alteration of one building block results in a modification of the whole architecture, suggesting that the arrangement of the different cuticular components must be under strict control. Moreover, the dramatic reduction of the thickness of the plant cuticle was deleterious for leaves whose protective layers then become more permeable to pesticides. Such a result was in good agreement with previous studies from an agrochemical company studying the interaction of sulfonylurea herbicides with certain organophosphorus insecticides by using field-testing conditions (Porpiglia et al., 1990). Furthermore, the reduction of the cuticle thickness and/or a low amount of epicuticular epoxides led to enhanced infection of the corn leaves by $C$. heterostrophus, shedding some light on the importance of the cuticle in plant-pathogen interaction.

Overall, our results validate, in planta, the involvement of a peroxygenase as a key enzyme in the formation of cuticle in plants that use $\mathrm{C} 18$ monomers. But the peroxygenase was also found present constitutively in plants coated with cutin poor in C18 monomers, raising the question of the physiological role of this enzyme in such plants. Nonetheless, the cuticle is evidently a key target for the mediation of the responses of the plant to its environment. 


\section{Experimental procedures}

\section{Chemicals}

PESTANAL grade organophosphorothioates (diazinon, disulfoton, paraoxon ethyl, parathion ethyl, parathion methyl, and terbufos) were purchased from Reidel-deHaën (Sigma, St Quentin, France). $\left[{ }^{14} \mathrm{C}\right]$ Metolachlor $\left(52 \mathrm{mCi} \mathrm{mmol}^{-1}\right)$ and $\left[{ }^{14} \mathrm{C}\right]$ primisulfuron $\left(14.8 \mathrm{mCi} \mathrm{mmol}^{-1}\right)$ were kind gifts from $\mathrm{Dr}$ R. Fonne (CIBA-GEIGY, Basel, Switzerland). $\left[{ }^{14} \mathrm{C}\right]$ Oleic acid $\left(52 \mathrm{mCi} \mathrm{mmol}^{-1}\right)$ was from NEN (Paris, France) and $\left[{ }^{14} \mathrm{C}\right]$-ring-UL-parathion (12.6 mCi mmol ${ }^{-1}$ ) from Sigma. Cutinase was generously provided by Unilever (Vlaardingen, the Netherlands).

\section{Plants}

Maize (Zea mays, var. LG11 from Limagrain, Clermont-Ferrand, France) and barley (Hordeum vulgare) seeds were soaked in water overnight. They were germinated in boxes $(27 \mathrm{~cm} \times 12 \mathrm{~cm} \times$ $12 \mathrm{~cm}$ ) coated with 1.5-cm depth-sterilized vermiculite saturated by $200 \mathrm{ml} 0.2 \%$ ethanol in water with (treated plants) or without (controls) 100 p.p.m. terbufos $(300 \mu \mathrm{M})$. Plants were grown in a chamber with controlled environment with constant temperature and humidity $\left(20^{\circ} \mathrm{C}\right.$ and $70 \%$, respectively) and a 16 -h photoperiod at 1700 lux light intensity. After 5 and 11 days, $100 \mathrm{ml}$ of sterile water was added to each box to avoid dehydration.

Oat (Avena sativa), beans (Vicia sativa and Glycine max.), and tobacco (Nicotiana tabaccum) seedlings were grown as above without treatment with terbufos.

\section{Pathogen}

The fungus $C$. heterostrophus (from the Université Catholique de Louvain-la-Neuve, Belgique) was grown on a V8 medium. The fungus culture was diluted with a peptonated water containing $0.05 \%$ Tween 20 to obtain a concentration of $10^{5}$ spores $\mathrm{ml}^{-1}$. Inoculations were made with a $10-\mu$ l droplet of this solution on the first leaf of 7-day-old maize seedlings.

\section{Isolation of cuticle and cutin monomers}

We have developed a method consisting in an extensive extraction of plant tissues by organic solvents, leaving a residue containing predominantly cell wall material and cuticle; this was followed by a hydrolysis of this residue with pure cutinase. The enzymatic hydrolysis of the major cuticle constituents allowed the preservation of the epoxy functions, which are otherwise largely destroyed by harsher chemical procedures. However, the ratio of the total $\mathrm{C} 16$ and C18 cutin monomers present in leaf cuticles of the plants analyzed here were very similar to those previously published (reviewed by Holloway, 1982).

Leaves $(1 \mathrm{~g})$ were carefully ground in a mortar under liquid nitrogen. After addition of $20 \mathrm{ml}$ distilled water, the slurry was vigorously shaken for at least $5 \mathrm{~min}$ then centrifuged at $3000 \mathrm{~g}$ for $15 \mathrm{~min}$. The resulting pellet was extracted three times with a mixture of chloroform:methanol $(2: 1, \mathrm{v} / \mathrm{v})$, then dried overnight at $40^{\circ} \mathrm{C}$. Cutin monomers were obtained from this powder $(0.6 \mathrm{mg})$ by the action of fungal cutinase $(0.5 \mathrm{mg})$ in $1 \mathrm{ml}$ of Tris buffer $0.1 \mathrm{M}, \mathrm{pH} 8$, during $16 \mathrm{~h}$ at $37^{\circ} \mathrm{C}$. Free cutin monomers were then extracted by the classical method described by Bligh and Dyer (1959). Cutin composition was analyzed by GC-MS after methylation of the acid function with ethereal diazomethane and silylation of hydroxyl groups with $\mathrm{N}, \mathrm{O}$-bis(trimethylsilyl) trifluoroacetamide (Interchim, France).

\section{Tests of permeability}

The influence of terbufos on leaf uptake of pesticides was determined on 7-day-old maize. $\left[{ }^{14} \mathrm{C}\right]$ Metolachlor (500 c.p.m. per $10 \mu \mathrm{l}$ ) dissolved in methanol or $\left[{ }^{14} \mathrm{C}\right]$ primisulfuron (500 c.p.m. per $10 \mu \mathrm{l}$ ) dissolved in acetate buffer $10 \mathrm{mM}, \mathrm{pH} 9$, containing $2 \%$ Tween 20 (Sigma) was applied to the first leaf as $0.5-\mu$ l droplets with a precision syringe. For each pesticide, five maize plants were treated and all treatments were performed in duplicate. Control plants were treated similarly with the solvents devoid of pesticide. At a given time, the leaves were harvested and the unabsorbed ${ }^{14} \mathrm{C}$ was removed from the leaf surface by sequential rinses with $2 \mathrm{ml}$ and $2 \times 1 \mathrm{ml}$ acetone. The leaves were ground in liquid nitrogen and extracted two times with $2 \times 2 \mathrm{ml}$ of acetone using an Ultra-Turrax homogenizer. The radioactivity in the leaf rinses and extracts was determined by liquid scintillation counting. The total ${ }^{14} \mathrm{C}$ recovery was $>95 \%$.

\section{Enzyme preparation}

Microsomes were prepared from seedlings as described previously for soybean (Blée and Schuber, 1989). The peroxygenase was solubilized with emulphogene $\mathrm{BC}-720$ and purified by ionexchange chromatography as described previously by Blée and Schuber (1989).

\section{Enzyme assays}

Oxidation of oleic acid by peroxygenase was carried out according to Blée and Schuber (1990). Alternatively, peroxygenase activity during maize germination was routinely measured with aniline as substrate (Blée and Schuber, 1989). Oxidative desulfuration of parathion was measured by incubating (final volume: $50 \mu \mathrm{l}$ ) the enzymatic fraction ( $1 \mu \mathrm{g}$ protein), $150 \mu \mathrm{M}\left[{ }^{14} \mathrm{C}\right]$-ring-UL-parathion, and $100 \mu \mathrm{M}$ cumene hydroperoxide in $10 \mathrm{mM}$ sodium acetate buffer ( $\mathrm{pH} 5.5$ ) containing $20 \%(\mathrm{v} / \mathrm{v})$ glycerol and $0.1 \%$ emulphogene. After a given time, the reaction was stopped by addition of $50 \mu \mathrm{l}$ acetonitrile. The sample was then applied to silica gel TLC plates and developed in diethylether:hexane:formic acid $(50: 50: 0.1, v / v)$. Radioactivity of the bands corresponding to parathion $\left(R_{\mathrm{f}} 0.72\right)$ and paraoxon $\left(R_{\mathrm{f}} 0.17\right)$ was then determined. Lipoxygenase activity was performed as previously described by Noehringer et al. (2000). The hydrolysis of epoxide by epoxide hydrolase was measured according to Blée and Schuber (1992). The P450-dependent $\omega$-hydroxylation of fatty acids was estimated following procedures described by Pinot et al. (1999). The measure of the enzymatic activity of elongase was performed according to the literature by Lessire et al. (1999).

\section{Inhibition of peroxygenase by organophosphorothioates}

To test the inhibition of peroxygenase by suicide inhibitors, enzymatic fraction ( $1 \mu \mathrm{g}$ protein) was pre-incubated in the presence of parathion $(20-150 \mu \mathrm{M}$ dissolved in $5 \mu \mathrm{l}$ ethanol) and $100 \mu \mathrm{M} 13$ hydroperoxy-octadecatrienoic acid in $20 \mu \mathrm{l} 0.1 \mathrm{M}$ acetate buffer $(\mathrm{pH} 5.5)$ during given times at $26^{\circ} \mathrm{C}$. Then, the incubates were diluted to $100 \mu \mathrm{l}$ with the same buffer and further incubated $5 \mathrm{~min}$ in the presence of $\left[{ }^{14} \mathrm{C}\right]$ oleic acid and residual activities determined. 
The $\mathrm{IC}_{50}$ values were determined by incubating the enzymatic fraction ( $1 \mu \mathrm{g}$ protein) in the presence of various concentrations of the organophosphorothioates $(0-500 \mu \mathrm{M}$ dissolved in $5 \mu \mathrm{l}$ ethanol), $20 \mu \mathrm{M}\left[{ }^{14} \mathrm{C}\right]$ oleic acid, and $1 \mathrm{mM}$ cumene hydroperoxide in $50 \mu$ acetate buffer $0.1 \mathrm{M}, \mathrm{pH} 5.5$. After $10 \mathrm{~min}$ incubation at $26^{\circ} \mathrm{C}$ the reactions were stopped by adding $50 \mu \mathrm{l}$ acetonitrile. The samples were applied to silica gel TLC plates and developed in a diethyl ether:hexane:formic acid (50:50:1) solvent system. Radioactivity of the band corresponding to the epoxide $\left(R_{\mathrm{f}} 0.62\right)$ and the residual oleic acid $\left(R_{\mathrm{f}} 0.84\right)$ was then determined.

\section{Microscopy techniques}

Fluorescent microscopy. Hand sections (about $50 \mu \mathrm{m}$ ) were stained with auramine-staining procedure $(0.01 \%, v / v)$ in Tris buffer (50 mM, pH 7.2; Heslop-Harrison, 1977) and analyzed with a microscope ZEISS equipped with mercury lamp HBO $\left(50 \mathrm{~W}\right.$ ), and combination of ZEISS filters $\mathrm{n}^{\circ} 2$ (excitation and barrier filters at 365 and $420 \mathrm{~nm}$, respectively).

Analytical transmitting electronic microscopy. Leaf samples were prepared following classical techniques (Glauert, 1975). Sections $(100 \AA)$ were contrasted by lead citrate following the procedure described by Reynolds (1963). Epoxide detection was realized according to Holloway et al. (1981).

Analytical procedures. Radioactivity was measured on TLC plates with a Berthold TLC linear detector LB 2821, and peaks integration was obtained by using the program CHROMA 1D (Packard Instrument Company, Rungis, France). Radioactivity was also determined in a liquid scintillation spectrometer (Minaxi Tricarb, series 4000, Packard). GC-MS analysis were performed on a Fisons MD 800 apparatus (Beverly, MA, USA) ionizing energy of $70 \mathrm{eV}$. The sample was injected directly into a DB-5-coated fused silica capillary column $(30 \mathrm{~m}, 0.25 \mathrm{~mm}$ internal diameter; J.W. Scientific, Interchim, Montluçon, France) with a temperature program of $20^{\circ} \mathrm{C} / \mathrm{min}$ to $100^{\circ} \mathrm{C}$ followed by $4^{\circ} \mathrm{C} / \mathrm{min}$ to $290^{\circ} \mathrm{C}$.

Spectrophotometric measurements were obtained with a Shimadzu model MPS-2000 spectrophotometer.

\section{Acknowledgements}

F.M.-L. is a postdoctoral researcher of the Fonds National pour la Recherche Scientifique of Belgium. We want to thank Pierre Mischler (IBMP, Strasbourg) for electronic photographs and René Lessire (CNRS-UMR 5544, Bordeaux) for elongase activity determination. Many thanks also to Uniliver for its generous gift of pure cutinase and to L. Dawn and L. Ruzo for correcting this manuscript.

\section{References}

Baur, P. (1997) Lognormal distribution of water permeability and organic solute mobility in plant cuticles. Plant Cell Environ. 20, 167-177.

Blée, E. (1991) Effect of the safener dichlormid on maize peroxygenase and lipoxygenase. Z. Naturforsch. C, 46, 920925.

Blée, E. and Schuber, F. (1989) Mechanism of S-oxidation reactions catalyzed by a soybean hydroperoxide-dependent oxygenase. Biochemistry, 28, 4962-4967.
Blée, E. and Schuber, F. (1990) Efficient epoxidation of unsaturated fatty acids by a hydroperoxide-dependent oxygenase. J. Biol. Chem. 265, 12887-12894.

Blée, E. and Schuber, F. (1992) Occurrence of fatty acid epoxide hydrolases in soybean (Glycine max). Purification and characterization of the soluble form. Biochem. J. 282, 711-714.

Blée, E. and Schuber, F. (1993) Biosynthesis of cutin monomers involvement of a lipoxygenase/ peroxygenase pathway. Plant $\mathrm{J}$. 4, 113-123.

Blée, E., Wilcox, A.L., Marnett, L.J. and Schuber, F. (1993) Mechanism of reaction of fatty acid hydroperoxides with soybean peroxygenase. J. Biol. Chem. 268, 1708-1715.

Bligh, E.G. and Dyer, W.J. (1959) A rapid method of total lipid extraction and purification. Can. J. Biochem. Physiol. 37, 911-917.

Butler, A.M. and Murray, M. (1997) Biotransformation of parathion in human liver: participation of CYP3A4 and its inactivation during microsomal parathion oxidation. Pharmacol. Exp. Ther. 280, 966-973.

DeZwaan, T.M., Carroll, A.M., Valent, B. and Sweigard, J.A. (1999) Magnaporthe grisea Pth11p is a novel plasma membrane protein that mediates appressorium differentiation in response to inductive substrate cues. Plant Cell, 11, 2013-2030.

Gilbert, R.D. and Dean, R.A. (1996) Chemical signals responsible for appressorium formation in the rice blast fungus Magnaporthe grisea. Phys. Mol. Plant Pathol. 48, 335-346.

Glauert, A.M. (1975) Fixation, Dehydration and Embedding of Biological Specimens. London: Portland Press.

Halpert, J. and Neal, R.A. (1981) Inactivation of rat liver cytochrome P450 by the suicide substrates parathion and chloramphenicol. Drug Met. Rev. 12, 239.

Heslop-Harrison, Y. (1977) The pollen-stigma interaction: pollen tube interaction in crocus. Ann. Bot. 41, 913-922.

Holloway, P.J. (1982) The chemical constitution of plant cutins. In The Plant Cuticle (Cutler, D.F. Alvin, K.L. and Price, C.E., eds) London/New York: Academic Press, pp. 45-84.

Holloway, P.J. Brown, G.A. and Wattendorff, J. (1981) Ultrahistochemical detection of epoxides in plant cuticular membranes. J. Exp. Bot. 32, 1051-1066.

Jenks, M.A., Rashotte, A.M., Tuttle, H.A. and Feldmann, K.A. (1996) Mutants in Arabidopsis thaliana altered in epicuticular wax and leaf morphology. Plant Physiol. 110, 377-385.

Kersteins, G. (1996) Signalling across the divide: a wider perspective of cuticular structure-function relationships. Trends Plant Sci. 1, 125-129.

Kolattukudy, P.E., Walton, T.J. and Kushwaha, R.P.S. (1973) Biosynthesis of the $\mathrm{C} 18$ family of cutin acids: $\omega$-hydroxyoleic acid, $\omega$ hydroxy-9,10-epoxystearic acid, 9, 10,18-trihydroxystearic acid, and their delta-12-unsaturated analogs. Biochemistry, 12, 4488-4498.

Lessire, R.S., Lucet-Levannier, C.K., Lellouche, J.P., Mioskowski, C. and Cassagne, C. (1999) Study of the 3-hydroxy eicosanoylcoenzyme $A$ dehydratase and (E)-2,3 enoyl-Coenzyme A reductase involved in acyl-Coenzyme A elongation in etiolated leek seedlings. Plant Physiol. 119, 1009-1015.

Noehringer, C., Scheel, D. and Blée, E. (2000) Lipoxygenase isoforms in elicitor-treated parsley cell suspension cultures. Biochem. Soc. Trans. 28, 827-829.

Ortiz de Montellano, P.R. and Correia, M.A. (1995) Inhibition of cytochrome P450 enzymes. In Cytochrome P450-Structure, Mechanism and Biochemistry (Ortiz de Montellano, P.R. and Correia, M.A., eds). New York/London: Plenum Press, pp. 305-364.

Pinot, F., Benveniste, I., Salaun, J.P., Loreau, O., Noel, J.P., Schreiber, L. and Durst, F. (1999) Production in vitro by the cytochrome P450CYP94A1 of major C-18 cutin monomers and potential 
messengers in plant-pathogen interactions: enantioselectivity studies. Biochem. J. 342, 27-32.

Porpiglia, P.J., Gillespie, G.R., Johnson, M.D. and Kreuz, K.E. (1990) Enhanced CGA-136872 activity in combination with insecticides. Abstr. Meet. Weed Sci. Soc. Am. 30, 6.

Pruitt, R.E., Vielle-Calzada, J.-P., Ploense, S.E., Grossniklaus, U. and Lolle, S.J. (2000) FIDDLEHEAD, a gene required to suppress epidermal cell interaction in Arabidopsis, encodes a putative lipid biosynthetic enzyme. Proc. Natl. Acad. Sci. USA, 97, 1311-1316.

Reynolds, E.S. (1963) The use of lead citrate at high $\mathrm{pH}$ as electron opaque stain in electron microscope. J. Cell Biol. 17, 209-212.

Riederer, M. and Schönherr, J. (1988) Development of plant cuticles: fine structure and cutin composition of Clivia miniata Reg. leaves. Planta, 174, 121-138.

Schönherr, J. (2000) Calcium chloride penetrates plant cuticles via aqueous pores. Planta, 212, 112-118.

Schreiber, L. (2001) Effect of temperature on cuticular transpiration of isolated cuticular membranes and leaf discs. J. Exp. Bot. 52, 1893-1900.
Schweizer, P., Jeanguenat, D., Whitacre, D., Métraux, J.-P. and Mösinger, E. (1996a) Induction of resistance in barley against Erysiphe graminis f.sp. hordei by free cutin monomers. Physiol. Mol. Plant Pathol. 49, 103-120.

Schweizer, P., Felix, G., Buchala, A., Müller, C. and Métraux, J.-P. (1996b) Perception of free cutin monomers by plant cells. Plant J. 10, 331-341.

Sieber, P., Schorderet, M., Ryser, U., Buchala, A., Kolattukudy, P., Métraux, J.-P. and Nawrath, C. (2000) Transgenic Arabidopsis plants expressing a fungal cutinase show alterations in the structure and properties of the cuticle and postgenital organ functions. Plant Cell, 12, 721-737.

Sinha, N. and Lynch, M. (1998) Fused organs in the adherent1 mutant in maize show altered epidermal wall with no perturbation in tissue identities. Planta, 206, 184-195.

Smith, H.B. (1999) More than just a surface thing: rice: infection by Magnaporthe grisea. Plant Cell, 11, 1815-1817.

Villena, J.F., Dominguez, E., Stewart, D. and Heredia, A. (1999) Characterization and biosynthesis of non-degradable polymers in plant cuticles. Planta, 208, 181-187. 